\title{
Study on the Interior Soft Decoration Art of Buddhist Temple Hall in Tibetan Buddhist Temple Buildings
}

\author{
Miaoru Wang \\ Art College, Southwest Nationality University, Chengdu, China \\ Email: 819575430@qq.com
}

How to cite this paper: Wang, M. R. (2020). Study on the Interior Soft Decoration Art of Buddhist Temple Hall in Tibetan Buddhist Temple Buildings. Open Journal of Social Sciences, 8, 284-290. https://doi.org/10.4236/jss.2020.84021

Received: April 3, 2020

Accepted: April 17, 2020

Published: April 20, 2020

Copyright () 2020 by author(s) and Scientific Research Publishing Inc. This work is licensed under the Creative Commons Attribution International License (CC BY 4.0).

http://creativecommons.org/licenses/by/4.0/

\section{(c) (i) Open Access}

\begin{abstract}
The interior soft decoration art of the Buddhist temple has a long history. Under the influence of the unique historical, geographical and religious conditions, it has formed a unique architectural artistic temperament, which will carry forward and inherit the Tibetan Buddhist art well. Through the field investigation of the Tibetan Buddhist temples in Aba Prefecture, Sichuan Province, this paper explores the artistic characteristics of the interior soft decoration of the Buddhist temples in Aba County, and analyzes them. From the deep analysis of the interior soft decoration art of the Buddhist temple with rich connotation, through the discussion of its color expression, pattern composition and decoration method, and the relationship with space coordination, this paper sums up the artistic characteristics of the interior soft decoration art of the Buddhist temple in Tibetan Buddhist architecture.
\end{abstract}

\section{Keywords}

Tibetan Buddhism, Temple Architecture, Buddhist Temple Hall, Interior Soft Decoration

\section{Introduction}

The inheritance and development of the architectural art of Tibetan Buddhist temples cannot be separated from the comprehensive effect of religion, region, nature, humanity and other factors (Long Zhu, 2011). Therefore, the study of the interior soft decoration art of Buddhist temples needs to be considered from multiple perspectives. The architectural art of Tibetan Buddhist temples located in Western Sichuan needs to be analyzed in combination with the local environment, religious atmosphere and the relationship between indoor and outdoor 
decoration of buildings, so as to promote the research on the indoor soft decoration art of Buddhist temples.

There live many ethnic groups in Aba County, Sichuan Province, including Zang, Qiang, Yi and Hui and other ethnic groups. While Tibetan Buddhism, as a leader, plays a very important role in Aba County. Buddhism was introduced to Tibetan area in the mid-seventh century, and then became Tibetan Buddhism by being affected by the Bon. Therefore, the architectural art of Tibetan Buddhism temples was influenced by three types of religious factors including Bon, Buddhism, and Tibetan Buddhism. In its development and evolution, Tibetan Buddhism architecture was influenced by the style of Chinese architecture, as a result its art form contains some style elements of Chinese art. Aba County is located in a high-altitude area. It has unique natural environment, snowy and valley landforms, plus the Bon's worship of nature; the art of local Tibetan Buddhist architectures is holy, rustic and distant.

\section{Summary of Interior Soft Decoration of Buddhist Temple Hall in Tibetan Buddhist Temple Building}

"Soft decoration" is relative to "hard decoration". It refers to the decoration content of later decoration after the completion of the basic hard decoration in the interior space. Such decoration content needs to be realized on the basis of easy to replace and move things. The research scope of interior soft decoration includes all kinds of ornaments, furniture furnishings, color matching and spatial organization. Through the arrangement of ornaments, furniture and reasonable color matching, the interior space can be fully expressed, and then meet the psychological and physiological needs of people in the space activities (Liu, 2014). In the interior space of the Buddhist temple in Aba Prefecture, soft decoration is the concentrated embodiment of the spiritual culture and concept of Tibetan Buddhism.

The exploration of the interior decoration art of the Buddhist temple halls in the architecture of Tibetan Buddhist temples requires constant analysis of the temple components. Through surveying, photographing, interviewing and other methods, the majority of temples in Aba Prefecture was surveyed and investigated, and the same interior decoration elements were compared and analyzed, as a result, the composition and art form was summarized of the interior decoration art of Buddhist temples in Tibetan Buddhist temple architecture.

Comprehensive comparative study has results as follows. The interior space of the Buddhist temple of Tibetan Buddhism generally adopts the typical "concave" type layout, including the front hall, the back hall and the corridor for turning scriptures, in which the front scripture hall is the largest indoor space covering the largest area, the small Buddhist temple is separated from the big scripture hall by a wall, and the corridor for turning scriptures is surrounded by the outer space of the inner space of the Buddhist temple hall (Liu, 2017).

As the main part of the Buddhist temple, Kunga Rawa hall accounts for about 
three quarters of the total area. It is the main space for monks to chant sutras and worship Buddha, and also the center for believers to chant sutras and praise Buddha. Especially in the major festivals of Tibetan Buddhism, this space is the most important place for worship activities. Therefore, the interior soft decoration art of Kunga Rawa hall is the most abundant: The main position of the scripture hall is the Buddha statue, the ribbon, the shrine and the altar decorated on it. On the altar are the incense burner, the Lama stupa made of copper or silver, the butter lamp and all kinds of instruments. In front of the altar are the merit boxes and the worship benches. The worship benches are covered with fabric cushions and fluffy blankets. In the "Mingjian" of the Buddha Hall (in Tibetan Buddhism, the space where the part of the atrium is illuminated by light is called Mingjian, and the surrounding area is called Mingjian The dark part is called the dark part or the secondary part, which is different from the Ming part of traditional Chinese architecture). In addition, there are tambourines and shelves, big chimes, wooden fish and other instruments in the Sutra hall. The small Buddha Hall and the scripture hall are separated by a solid wall, and the interior space is narrow, which is in contrast with the spacious and ornate scripture hall. The main soft decorations are the Buddha statues, shrines, ribbons decorated on them, various silver or copper instruments, butter lamps, etc. on the altar, as well as the fabric kneeling pads and fluffy blankets covered on the bench. Generally, there is no decoration in the transit corridor space, and the main devices are the transit cylinders with exquisite patterns carved on the surface.

To sum up, the interior soft decoration of Tibetan Buddhist temple buildings mainly consists of fabrics with complex patterns and gorgeous colors, exquisite metal instruments and wooden furniture with exquisite patterns. The sum of these elegant and flexible soft decorations and the hard decoration such as walls and building components painted with colorful paintings complement each other, forming a gorgeous and mysterious interior soft decoration style of Buddhist temples.

\section{Analysis of the Color Expression of the Interior Soft Decoration Art of the Buddhist Temple in the Tibetan Buddhist Temple Building}

In the interior space of buildings, color has a great influence on the soft decoration effect of the whole interior. It is first perceived directly by people, so it can be called a visual language (Zeng, 2010). In the field of interior soft decoration of Buddhist temples, the expression of color influences the expression of interior soft decoration in its unique way. The color expression of Tibetan Buddhism needs to be explored from its own essence, and the color expression of the interior soft decoration of temple building should also be analyzed from the category of the overall color system of the temple.

Through a survey of the Tibetan Buddhist temples in Baodian Temple, Sang- 
dan Temple and Langyi Temple in Aba Prefecture, it can be found that although the color processing is different, there are still rules to follow. Generally speaking, the colors of Tibetan Buddhism are red, yellow, blue, green and white. They have their own decoration principles and methods in architecture, sculpture, painting, clothing and interior decoration, and they are coordinated and unified with each other.

Red and yellow are the religious colors of Tibetan Buddhism. The use of red in Tibetan Buddhism is closely related to the ancient Bon religion of the Tibetan nationality. The Tibetan people regard red as a symbol of rights and honor, as well as a representative color of bravery and good war. The noble position of yellow in Buddhism is directly related to the Buddha Sakyamuni. The combination of red and yellow represents the noble, holy and faith in Tibetan Buddhism. Therefore, these two most noble colors are applied to the most important temple buildings and monks' clothes, which cannot be used by the general public. Accordingly, in the interior soft decoration, these two colors are widely used in the furniture such as Buddha statues, shrines and shrines, and yellow ribbons are also decorated on the Buddha statues and shrines. Blue represents water in Tibetan Buddhism, which symbolizes wisdom, greatness and eternity. Cyan symbolizes eternal rebirth and brightness. If the decoration technique of gradual fading is adopted, it symbolizes the process of rebirth and reappearance of brightness. White has the meaning of solemnity, purity and holiness.

In the interior soft decoration of the Buddha Hall, these five main colors are mainly used together except for the above-mentioned large-area solid colors. For example, the canopy hanging on the top beam of the Buddha statue in the "Ming Dynasty" is composed of these five colors, which are gorgeous and bright; the color flags covering the beam near the Buddha statue, the victory building hanging between the pillars, and the color flags hanging on the surface of the pillars are also the combination of the five main colors.

\section{Study on the Pattern of Interior Soft Decoration Art of Buddhist Temple in Tibetan Buddhist Temple Building}

Under the washing of thousands of years of history, Tibetan Buddhist art precipitated its own unique decorative patterns. The patterns of the Buddha Temple in Aba County are rich, and different shapes and themes are designed according to different occasions. In the Buddhist scripture hall and the wall of the small Buddhist hall, the murals with the theme of God and Buddha are mainly used. Compared with the murals with the theme of God and Buddha, more plant patterns, auspicious cloud patterns, palindromes, auspicious eight treasures patterns, and harmony four auspicious patterns are used in the interior soft decoration of the Buddhist hall. The following is a classification description for the main pattern types of the interior decoration art in the halls of the temples.

Among the above patterns, the auspicious eight treasures pattern is the most religious and artistic. "Eight auspicious treasures", is also known as "eight auspi- 
cious symbols" or "eight auspicious images". The eight auspicious treasures are eight auspicious symbols of auspiciousness. They all contain their own unique, beautiful symbols such as completeness, wisdom, liberation and purity. Their images are also used in decorative patterns to form the "eight auspicious patterns" that have been handed down from generation to generation. The auspicious eight treasures pattern is widely used in the interior soft decoration of the Buddhist temple. The decoration methods include sculpture, sculpture, plane painting, weaving and other techniques. For example, in garden temple in Aba County, Sichuan Province, the design of auspicious eight treasures pattern is painted on the inside of the Buddhist temple, the cabinet door of the wall cabinet, and the drawer surface of the desk. The design of silk in Shengli building suspended between the pillars of the Buddhist scripture hall is also presented auspicious eight treasures pattern; the facade of the table and kneeling stool is painted with auspicious cloud pattern and auspicious eight treasures pattern.

Plant pattern, palisade and auspicious cloud pattern are mostly used in the hard furniture display in the Buddha Hall. For example, palisade is painted or carved on the waist of the Tibetan table, the frame of the Buddha niche and the frame of the niche in the Buddha Hall of golden temple. In Sanskrit, the palisade means auspiciousness and the gathering of various merits and virtues, which means auspiciousness and completeness. The cushions placed in the square hall for monks to chant sutras are woven of wool or hemp, presenting the pattern of palisade and entwined branches and rattan, also known as "longevity rattan pattern", which means good luck and continuity. Auspicious cloud patterns are often seen in the facade painting or sculpture of kneeling stool.

\section{The Relationship between Interior Soft Decoration Art and Interior Space Coordination in Tibetan Buddhist Temple Architecture}

The relationship between interior soft decoration and interior space coordination needs to be considered from multi-dimensional perspective. When it comes to the field of interior soft decoration art of Buddhist temples in Tibetan Buddhism, it is necessary to study the coordination between the fabric and artifact in the interior of the Buddhist temples and the tables, thrones, kneeling benches, pillars, etc. in the Buddhist temples, the coordination between the color banners, canopy, statues and pillars in the vertical interface, and the suitability of various soft decorations in color organization.

The space of Sutra hall in Tibetan Buddhist temple is generally spacious, which requires soft decoration to decorate and adjust the large open space. The color flags and Huagai hanging from the roof enhance the vertical space diversity. Combined with the furniture furnishings such as Buddha statue, table, closet, kneeling stool, the interior space of the whole Sutra hall is well enriched, and the spiritual mood of Tibetan Buddhism can be achieved Comprehensive expression. From the point of view of decorative color elements, the interior of the en- 
tire interior space is heavily colored with gorgeous and colorful decoration techniques. Through indoor soft decoration, the whole space is rendered complex but not messy. Therefore, the interior soft decoration of Tibetan Buddhist buildings has the function of adjusting and modifying the interior space of the Buddha Hall (Liu \& Liu, 2009).

Because of the unique modeling way of Tibetan Buddhist temple architecture, the interior space of the Buddhist temple is relatively dim. This kind of light presents a mysterious and heavy feeling to people. In addition, the indoor Buddha statues and the large murals that represent the theme of the god Buddha set off a very solemn and dignified atmosphere in the interior space. The addition of the interior soft decoration can soften this atmosphere appropriately, soft fabrics and ribbons Such Buddha ornaments also soften the sense of hardness brought by hard ornaments. Some large-scale instruments in the Buddha Hall also divide the large space. The furnishings of table, throne, kneeling stool and other household furnishings strictly define each functional space. As the only ornament furnishings in the space, the warping barrel of the warping Gallery clearly defines the warping gallery space. Therefore, the interior soft decoration of Tibetan Buddhist temple has the function of softness and defining the interior space of Buddhist temple.

\section{Conclusion}

To sum up, the interior soft decoration art of Buddhist temple in Tibetan Buddhist architecture has a unique color expression form; the decorative pattern is unique and has its own unique decorative expression method; the unique interior space form of Buddhist temple is organized. After a long history of precipitation, the interior soft decoration of Buddhist temples in Tibetan Buddhism has formed its unique religious artistic characteristics: complicated and gorgeous, mysterious and solemn. To study the architectural art, we need to analyze the interior soft decoration art. Therefore, the research on the interior soft decoration art of the Buddhist temple in Tibetan Buddhism is also an essential content, which needs to be explored and studied constantly.

Through the survey and analysis of the Tibetan Buddhist temples in Aba County, a deeper understanding of the interior decoration will provide cultural support for future study on the interior decoration art of Tibetan Buddhist temples. The unique interior decoration style of Tibetan Buddhist temples in Aba County is an exploration of the aesthetic direction of the architecture of Tibetan Buddhist temple. It also enriches the interior decoration arts. The study of its color and patterns provide a diverse element basis for the modern interior decoration, cultural and creative product design, clothing design and other fields.

\section{Acknowledgements}

This project is funded by the graduate innovative scientific research project [grant number: CX2019SZ184] of Southwest University for nationalities. 


\section{Conflicts of Interest}

The author declares no conflicts of interest regarding the publication of this paper.

\section{References}

Liu, C. (2014). Art Design and Interior Soft Decoration Design. Modern Decoration (Theory), 10, 38-39.

Liu, W. (2017). Analysis of the Aesthetic Characteristics of the Structure and Interface Decoration of the Main Hall of Baodian Temple. Tibetan Art Research, No. 2, 28-35.

Liu, W., \& Liu, B. (2009). Harmonious Space Analysis of the Transition of Architectural External Space. Journal of Hebei University of Engineering (Natural Science Edition), $26,20-23+39$.

Long Zhu, D. J. (2011). Study on the Architectural Culture of Tibetan Buddhist Temples. Thesis, Beijing: Minzu University of China.

Zeng, S. J. (2010). Study on Aesthetic Culture of Interior Soft Decoration. Thesis, Changsha: Hunan University. 